\title{
Segmented Poly(urethane-urea)s Synthesized Directly from Isocyanate-Terminated Prepolymers and Masked Diamines III. Kinetic and Mechanistic Study on Polymerization Reactions
}

\author{
Hiroyuki Hanahata, ${ }^{\dagger}$ Emiko Yamazaki, Jun-ichi Hiwatari, \\ and Yoshiharu KITAHAMA ${ }^{\dagger \dagger}$ \\ Central Laboratory, Asahi Chemical Industry Co., Ltd., \\ 11-7 Hacchonawate-cho, Takatsuki, Osaka 569, Japan
}

(Received January 29, 1997)

\begin{abstract}
The direct synthesis of segmented poly(urethane-urea)s (DSPUU) from an isocyanate-terminated prepolymer (ITPP) and reaction products (AE) from acetone and ethylenediamine consisting of $N$-isopropylideneethylenediamine (1), $N, N^{\prime}$-diisopropylideneethylenediamine (2), 2,2-dimethylimidazolidine (3), water and the unreacted diamine was kinetically investigated. The following elementary reactions forming the desired urea structure linkage take place simultaneously in the absence of an acid at $40^{\circ} \mathrm{C}$; (i) reaction of NCO groups with amino groups of the unreacted diamine and (1), (ii) direct reaction of NCO groups with (3), (iii) ring opening reaction of (3), and (iv) reaction of NCO groups with the ketimine groups in (1) and (2). The side reactions of NCO groups with water (Urea II formation reaction) catalyzed by both the ketimine groups and the imino groups occurred. Dramatic decrease of the yield of Urea II in the presence of acetic acid is attributed to the acid-catalyzed ring opening of the imino groups of (3) in particular and acid-catalyzed hydrolysis of the ketimine groups.

KEY WORDS Poly(urethane-urea)s / Bulk Polymerization / Isocyanate-Terminated Prepolymer / Masked Diamines / Polymerization Kinetics / Demasking Reactions / Direct Reactions /
\end{abstract}

For clarification of the mechanism of the direct synthesis of segmented poly(urethane-urea)s (DSPUU reaction) from an isocyanate-terminated prepolymer (ITPP) and acetone-masked ethylenediamine (AE), ${ }^{1}$ consisting of $N$-isopropylideneethylenediamine (1), $N, N^{\prime}$-diisopropylideneethylenediamine (2), 2,2-dimethylimidazolidine (3), and water ( cant reactions involved in DSPUU reactions in the ab- sence of an acid catalyst are direct reactions of isocyanate (NCO) groups with (1) and (2) as well as with $(3)^{1,2}$ (see $\square$ in Scheme 1). These reactions were classified into the first category. The preceding paper ${ }^{3}$ elucidated the kinetics of masking and demasking reactions for AE. Important reactions belonging to the second category were found to be the water- and acid-catalyzed ring opening of (3) and acid-catalyzed hydrolysis reactions of

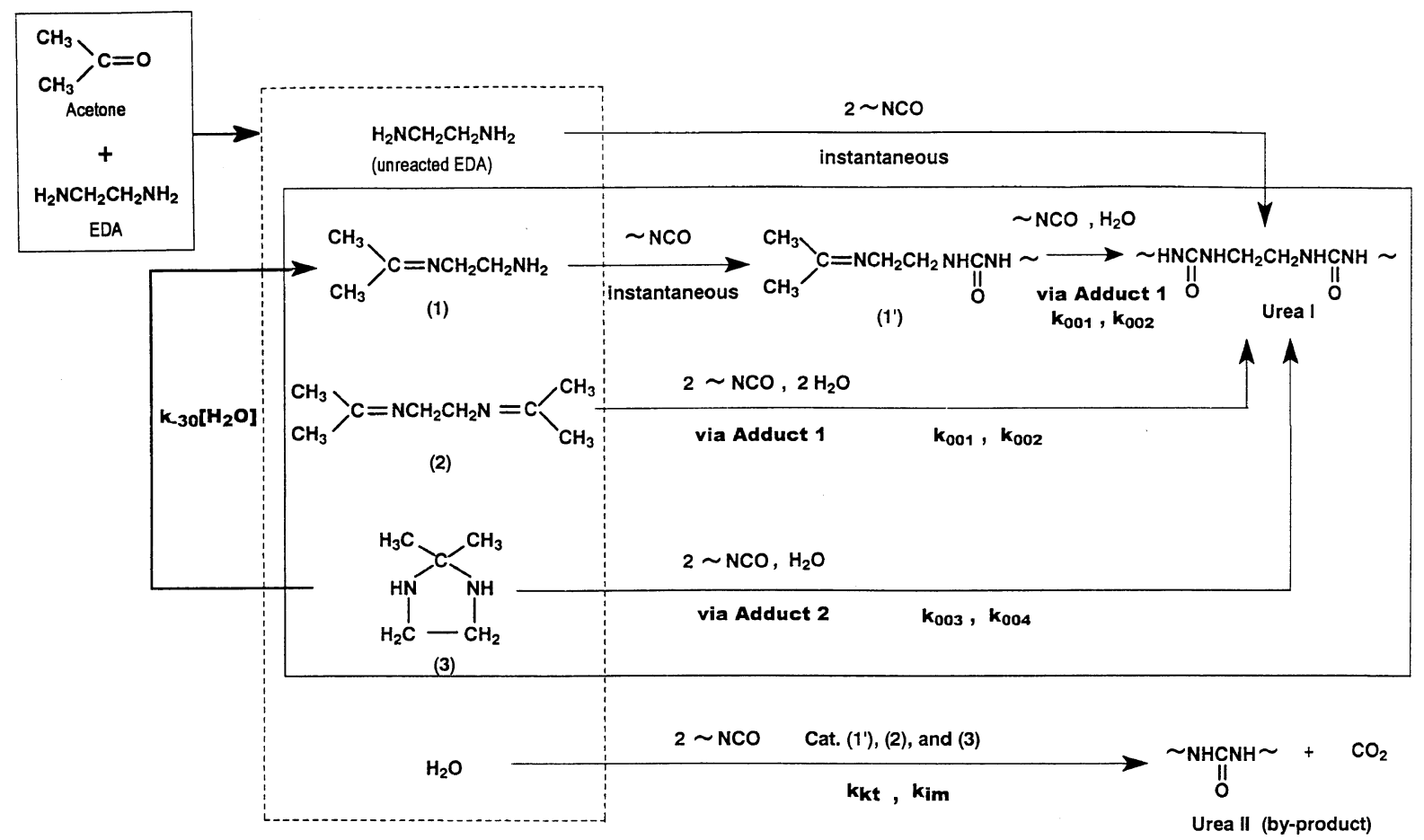

Scheme 1. Elementary DSPUU reactions in the absence of acid catalyst.

\footnotetext{
${ }^{\dagger}$ To whom correspondence should be addressed

${ }^{\dagger \dagger}$ Present address: Japan Elastomer Co., Ltd., Oaza Nakanosu 2, Oita 870-01, Japan.
} 


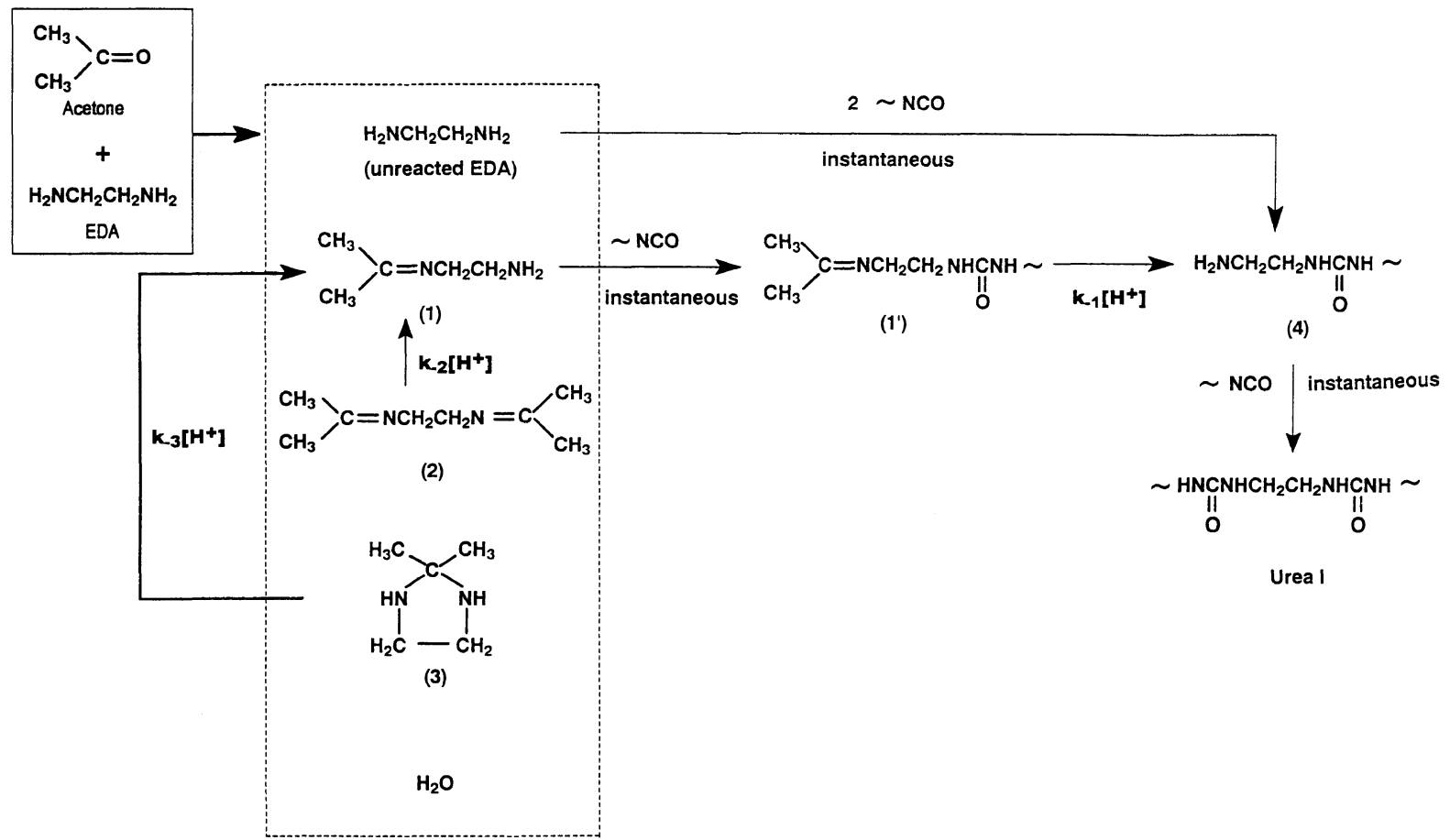

Scheme 2. Urea I formation through acid-catalyzed hydrolysis reaction of ketimine groups.

\section{(1) and (2) (Schemes 1 and 2). ${ }^{3}$}

This paper estimates the rate and catalyst constants of elementary reactions in the first category. The dominant and simultaneous elementary reactions belonging to the first and second categories in DSPUU reactions are made clearer by comparing (1) experimental rates of consumption of NCO groups during the DSPUU reactions and (2) the yields of the by-product (Urea II) formed from the reaction of NCO groups with water, to the corresponding values (1)' and (2)' calculated by solving numerically a set of simultaneous rate equations including all elementary reactions belonging to the above two categories. The roll of an acid for vanishing the yield of Urea II $^{1}$ is also clarified, finally leading to clarification of overall mechanism of DSPUU reactions in the absence and presence of the acid catalyst.

\section{EXPERIMENTAL}

Model Reactions of ITPP with Ketimine or Imidazolidine

For estimating the rate and catalyst constants of the reactions of the isocyanate-terminated prepolymer (ITPP) with (1), (2), and (3), the following two model reactions were examined. Since it was impossible to isolate the reaction products (AE) from acetone with EDA, $N$-isopropylidenebutylamine and 2-pentamethylenoimidazolidine were used as the model of ketimine and imidazolidine in an AE sample, respectively.

Reaction of ITPP with N-Isopropylidenebutylamine. One hundred grams of ITPP (NCO content, $0.679 \mathrm{~mol}$ ) obtained from the reaction of excess molar of 4,4'methylenediphenyl diisocyanate (MDI) with poly(tetramethylene oxide) (PTMO, $\left.\bar{M}_{n}=2010\right)$ were mixed with $7.08 \mathrm{~g}(0.0625 \mathrm{~mol}$ as $91 \%$ purity $)$ of $N$-isopropylidenebutylamine $^{4}$ and $1.13 \mathrm{~g}(0.0625 \mathrm{~mol})$ of water using a mixing device ${ }^{1}$ for $5 \mathrm{~s}$, followed by tracing the concentration change of $\mathrm{NCO}$ groups at $40^{\circ} \mathrm{C}$ for $400 \mathrm{~s}$ by FT-IR described later. By ${ }^{13} \mathrm{C}$ NMR, the reaction product was found to contain $58.3 \mathrm{~mol} \%$ of Urea $\mathrm{I}^{\prime}$, the urea linkage formed by the reaction of an NCO group of ITPP with $n$-butylamine. The rest $(41.7 \mathrm{~mol} \%)$ was Urea II. The detailed preparation procedure of the above ITPP and operating conditions of ${ }^{13} \mathrm{C}$ NMR were described in ref 1 .

Since the rate of hydrolysis reaction of a ketimine analogue is negligibly slow ${ }^{3}$ for the reaction pathway of Urea I' formation, it should be recognized that an intermediate compound is formed first from the direct reaction of the ketimine group with $\mathrm{NCO}$ groups ${ }^{2,5}$ (corresponding rate constant is defined as $k_{001}$ ), followed by the hydrolysis reaction (rate constant of $k_{002}$ ), giving Urea I'. Urea II is formed by the reaction of ITPP with water, supported by the ketimine catalysis ${ }^{1}$ (the catalyst constant of $k_{\mathrm{kt}}$ ).

$k_{001}, k_{002}$, and $k_{\mathrm{kt}}$ were estimated by fitting the calculated plots of $[\mathrm{NCO}] /[\mathrm{NCO}]_{0}$ and calculated molar fraction of Urea II (see, APPENDIX) to the above experimental plots and the molar fraction by the least-square fitting method.

Reaction of ITPP with 2-Pentamethylenoimidazolidine. The model reaction of $100.0 \mathrm{~g}$ of ITPP $(0.679 \mathrm{~mol})$, $10.63 \mathrm{~g}$ of the reaction products from cyclohexanone with EDA containing $0.0625 \mathrm{~mol}$ of 2-pentamethylenoimidazolidine as $93 \%$ purity, and $0.0625 \mathrm{~mol}$ of water was carried out in chloroform (109.9 g), giving a mixture of Urea I' and Urea II. The preparation procedure of the reaction products is shown in ref 2 . Kinetic measurements by FT-IR were also performed during this reaction. The molar fraction of Urea II was $26.0 \%$ in this case. Note that this reaction was inevitably carried out in chloroform solution due to the extremely fast reaction in bulk.

Subject to the analogy of this reaction pathway to that of the above model ketimine-ITPP reaction, ${ }^{2,6}$ rate constants such as $k_{003}$ for the addition reaction and $k_{004}$ 
for the hydrolysis reaction as well as the catalyst constant $k_{\mathrm{im}}$ of the imino groups were estimated in the similar manner to the case of model ketimine-ITPP reaction.

\section{Kinetic Measurements}

Figure 1 schematically shows an ATR (attenuated total reflection) holder for kinetic measurements in DSPUU reactions. The holder is composed of an IRE ( $\mathrm{ZnSe}$ crystalline rod, $45^{\circ}, 84-\mathrm{mm}$ long $\times 9-\mathrm{mm}$ wide $\times 6-\mathrm{mm}$ high) and a lid for sealing a sample with nitrogen gas. The consumption of NCO groups at various reaction times was measured when DSPUU samples (DSPUU211) were synthesized in the literature. ${ }^{1}$ The temperature rise during the measurements for all DSPUU reactions was within $5 \%$ owing to the relatively low concentrations of NCO and amino groups. It was inaccurate to detect concentrations of other functional groups such as the ketimine and imino groups by this FT-IR method since the characteristic ketimine peak $\left(1665 \mathrm{~cm}^{-1}\right)$ was close to those of Urea I $\left(1635 \mathrm{~cm}^{-1}\right.$ (hydrogen-bonded)) and Urea II (1639 $\mathrm{cm}^{-1}$ (hydrogen-bonded)) and the extremely weak peak of the imino group $\left(1600 \mathrm{~cm}^{-1}\right)$.

\section{RATE EQUATIONS}

DSPUU reactions in the absence and presence of an acid catalyst are the elementary reactions shown in Schemes 1 and 2, respectively. The Urea I formation reaction of NCO groups (i) with the amino groups of unreacted EDA and (1) which is instantaneously transformed to $\left(\mathbf{1}^{\prime}\right)^{7}$ and (ii) with the ketimine groups of $\left(\mathbf{1}^{\prime}\right)$ and (2) as well as the imidazolidine (3) in the presence

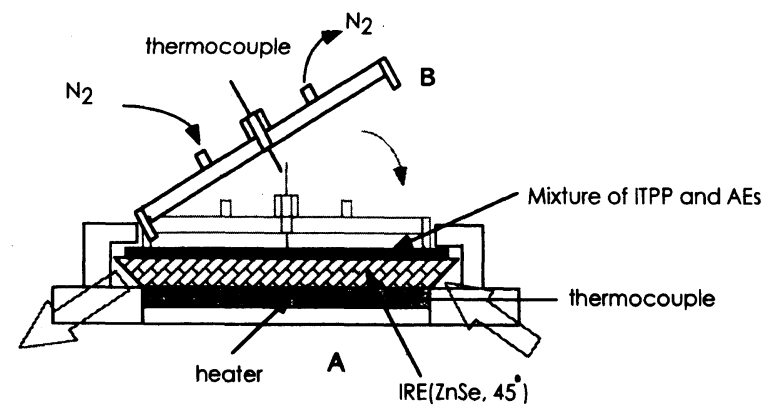

Figure 1. Schematic diagram of the ATR (attenuated total reflection) holder for kinetic measurements; A, ZnSe crystalline rod with heating elements and temperature controller; B, a lid for sealing a sample by nitrogen gas. of water via Adducts 1 and 2 (Scheme 3), respectively ${ }^{1,2}$ (these reactions belong to the category of the direct reactions). The water-catalyzed ring opening of (3) to form (1) also takes place at the same time. ${ }^{3}$ (iii) the side reaction of $\mathrm{NCO}$ groups with water to form Urea II catalyzed by the ketimine groups of $\left(\mathbf{1}^{\prime}\right)$ and $(\mathbf{2})$ as well as the imino groups of (3) and the Adduct 2 also occurs. ${ }^{1,2}$

In the presence of the acid catalyst, (iv) the reactions of NCO groups with the amino groups reformed from the ketimine groups of $\left(\mathbf{1}^{\prime}\right)$ and (2) as well as the imidazolidine (3) and (v) the acid-catalyzed ring opening of (3) are significant (these reactions belong to the category of the demasking reactions in Scheme 2). ${ }^{3}$ It should be noted that the acid-catalyzed hydrolysis of the above Adducts 1 and 2 are neglected in this simulation because formation reactions of these adducts were found to be rate determining as described later.

Taking into account the extremely fast reactions of $\mathrm{NCO}$ groups with amino groups ${ }^{7}$ regenerated from $\left(\mathbf{1}^{\prime}\right)$, (2), and (3), it can be assumed in the rate equations for the model of DSPUU reaction that the reverse reactions do not principally occur (that is, negligible) and therefore the regeneration rates of the amino groups from $\left(\mathbf{1}^{\prime}\right)$, (2), and (3), respectively, may be regarded as the rate determining reactions to form the main product (Urea I). The reformation rate of amino groups from (1') may be considered the same as that of (1).

The simultaneous rate equations (eq $1-11$ ) could be solved by a computer after substituting the six rate and catalyst constants estimated in EXPERIMENTAL, together with four constants previously determined ${ }^{3}$ (all listed in Table I) and the initial concentrations of the functional groups in AE samples and NCO groups of ITPP (Table II). All numerical calculations were performed using the Runge-Kutta fourth order method on a work station Model INDY, manufactured by Silicon Graphics Inc., U.S.A.

The rate of increase in the concentrations of the amino groups reformed from $\left(\mathbf{1}^{\prime}\right),(\mathbf{2})$, and (3) is expressed in eq 1 , neglecting the rate constants of the hydrolysis reactions of the ketimine groups in the absence of the acid. ${ }^{1}$ Note again that the amino groups thus formed are consumed instantaneously by reactions with $\mathrm{NCO}$ groups, forming Urea I. EDA contained in AE samples is also consumed at the beginning of the reactions.

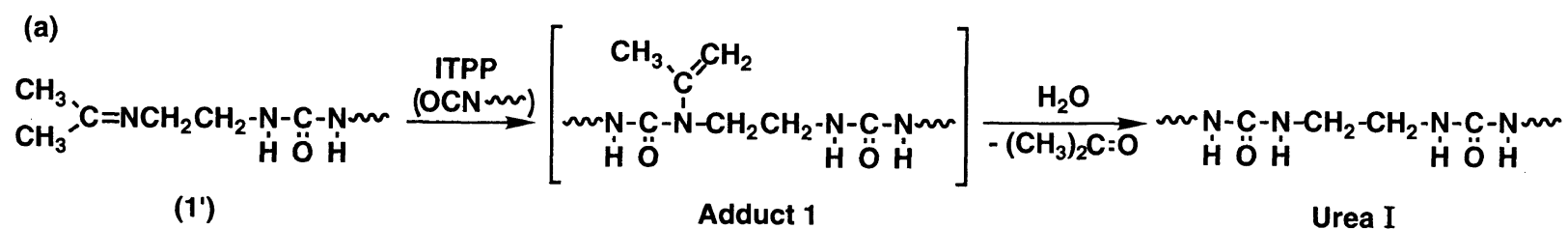

(b)

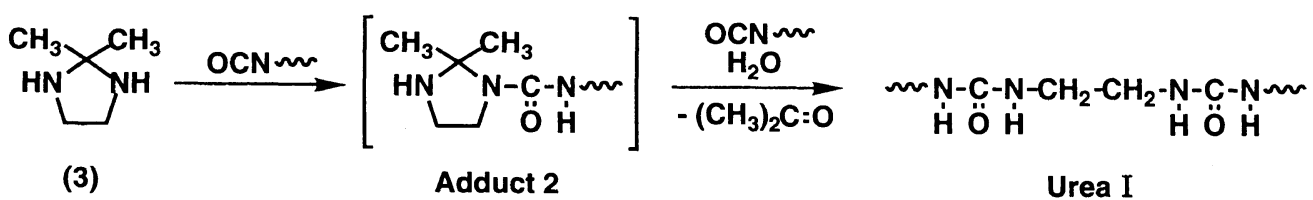

Scheme 3. Formation pathways of Adducts 1 and 2 from (1') and (3), respectively. 


$$
\begin{aligned}
& \mathrm{d}\left[\mathrm{NH}_{2}\right] / \mathrm{d} t=k_{-1}\left[\mathrm{H}^{+}\right]\left[\left(\mathbf{1}^{\prime}\right)\right]\left[\mathrm{H}_{2} \mathrm{O}\right] \\
& \quad+2 k_{-2}\left[\mathrm{H}^{+}\right][(2)]\left[\mathrm{H}_{2} \mathrm{O}\right]+\left(k_{-30}\left[\mathrm{H}_{2} \mathrm{O}\right]\right. \\
& \left.\quad+k_{-3}\left[\mathrm{H}^{+}\right]\right)[(3)]
\end{aligned}
$$

where $\left[\mathrm{NH}_{2}\right],\left[\left(\mathbf{1}^{\prime}\right)\right],[(2)],[(3)]$, and $\left[\mathrm{H}_{2} \mathrm{O}\right]$ represent the concentrations of the amino groups, $\left(\mathbf{1}^{\prime}\right),(\mathbf{2}),(3)$, and water, respectively. The catalyst constants of hydrolysis reactions of $\left(\mathbf{1}^{\prime}\right)$ and (2) are denoted as $k_{-1}$ and $k_{-2}$. The catalyst constants of $k_{-30}$ and $k_{-3}$ are those for the water- and acid-catalyzed reformation reactions of (1) from (3) by tautomeric relation.

Similarly, the rate of increase in the concentration of acetone is given by eq 2 .

$$
\begin{aligned}
& \mathrm{d}[\text { acetone }] / \mathrm{d} t=k_{-1}\left[\mathrm{H}^{+}\right]\left[\mathrm{H}_{2} \mathrm{O}\right]\left[\left(\mathbf{1}^{\prime}\right)\right] \\
& \quad+2 k_{-2}\left[\mathrm{H}^{+}\right][(2)]\left[\mathrm{H}_{2} \mathrm{O}\right]+2 k_{002}[\mathrm{Add} 1]\left[\mathrm{H}_{2} \mathrm{O}\right] \\
& \quad+k_{004}[\mathrm{Add} 2]\left[\mathrm{H}_{2} \mathrm{O}\right]
\end{aligned}
$$

where $k_{002}$ and $k_{004}$ denote the rate constants of the hydrolysis reactions of the Adduct 1 and Adduct 2; the former is derived from the addition reaction of $\mathrm{NCO}$ groups with the ketimine groups of $\left(\mathbf{1}^{\prime}\right)$ and (2) and the latter with (3), respectively.

Next the rates of decrease in the concentrations of $\left(\mathbf{1}^{\prime}\right)$, (2), and (3) (subject to water catalysis ${ }^{8}$ ), respectively, can be expressed as follows, considering that $\left(\mathbf{1}^{\prime}\right)$ is formed instantaneously from (1);

$$
\begin{aligned}
& -\mathrm{d}\left[\left(\mathbf{1}^{\prime}\right)\right] / \mathrm{d} t=k_{-1}\left[\mathrm{H}^{+}\right]\left[\left(\mathbf{1}^{\prime}\right)\right]\left[\mathrm{H}_{2} \mathrm{O}\right] \\
& \quad-2 k_{-2}\left[\mathrm{H}^{+}\right][(2)]\left[\mathrm{H}_{2} \mathrm{O}\right]+k_{001}\left[\left(\mathbf{1}^{\prime}\right)\right][\mathrm{NCO}] \\
& -\left(k_{-30}\left[\mathrm{H}_{2} \mathrm{O}\right]+k_{-3}\left[\mathrm{H}^{+}\right]\right)[(3)] \\
& -\mathrm{d}[(2)] / \mathrm{d} t=2 k_{-2}\left[\mathrm{H}^{+}\right][(2)]\left[\mathrm{H}_{2} \mathrm{O}\right] \\
& \quad+2 k_{001}[(2)][\mathrm{NCO}] \\
& -\mathrm{d}[(3)] / \mathrm{d} t=\left(k_{-30}\left[\mathrm{H}_{2} \mathrm{O}\right]+k_{-3}\left[\mathrm{H}^{+}\right]\right)[(3)] \\
& \quad+2 k_{003}[(3)][\mathrm{NCO}]
\end{aligned}
$$

where $k_{001}$ and $k_{003}$ denote the rates of addition reactions of NCO groups with the ketimine groups of $\left(\mathbf{1}^{\prime}\right)((\mathbf{2}))$ and imino group of (3), forming the Adducts 1 and 2 (Scheme 3), respectively.

The rate of decrease in a water concentration is given by eq 6 , considering the catalysis of the ketimine and the imino groups of (3) and Adduct 2 for the NCO-water reaction $\left(k_{\mathrm{kt}}\right.$ and $k_{\mathrm{im}}$ are the catalyst constants by the ketimine group and imino group, respectively). The rate constant $\left(5.9 \times 10^{-5} \mathrm{~kg} \mathrm{~mol}^{-1} \mathrm{~s}^{-1}\right)$ of ITPP and water ${ }^{9}$ was small and therefore neglected.

$$
\begin{aligned}
& -\mathrm{d}\left[\mathrm{H}_{2} \mathrm{O}\right] / \mathrm{d} t=k_{-1}\left[\mathrm{H}^{+}\right]\left[\mathrm{H}_{2} \mathrm{O}\right]\left[\left(\mathbf{1}^{\prime}\right)\right] \\
& \quad+2 k_{-2}\left[\mathrm{H}^{+}\right]\left[\mathrm{H}_{2} \mathrm{O}\right][(\mathbf{2})]+\left\{k _ { \mathrm { kt } } \left(\left[\left(\mathbf{1}^{\prime}\right)\right]\right.\right. \\
& \left.\quad+2[(\mathbf{2})])+k_{\mathrm{im}}(2[(\mathbf{3})]+[\mathrm{Add} 2])\right\}[\mathrm{NCO}]\left[\mathrm{H}_{2} \mathrm{O}\right] \\
& \quad+k_{002}[\mathrm{Add} 1]\left[\mathrm{H}_{2} \mathrm{O}\right]+k_{004}[\mathrm{Add} 2]\left[\mathrm{H}_{2} \mathrm{O}\right]
\end{aligned}
$$

The rate of decrease in the concentrations of the Adducts 1 and 2 can be written in eq 7 and 8 as,

$$
\begin{aligned}
& -\mathrm{d}[\mathrm{Add} 1] / \mathrm{d} t=k_{001}\left(2[(\mathbf{2})]+\left[\left(\mathbf{1}^{\prime}\right)\right]\right)[\mathrm{NCO}] \\
& -k_{002}[\mathrm{Add} 1]\left[\mathrm{H}_{2} \mathrm{O}\right] \\
& -\mathrm{d}[\mathrm{Add} 2] / \mathrm{d} t=2 k_{003}[(3)][\mathrm{NCO}] \\
& \quad-k_{004}[\mathrm{Add} 2]\left[\mathrm{H}_{2} \mathrm{O}\right]
\end{aligned}
$$

By considering eq 1, A5 (see Appendix), 7, and 8, the rate of increase in Urea I concentration is given by eq 9 .

$$
\begin{aligned}
& \mathrm{d}[\text { Urea I }] / \mathrm{d} t=k_{002}[\mathrm{Add} 1]\left[\mathrm{H}_{2} \mathrm{O}\right] \\
& \quad+2 k_{004}[\mathrm{Add} 2]\left[\mathrm{H}_{2} \mathrm{O}\right]+k_{-1}\left[\mathrm{H}^{+}\right]\left[\left(\mathbf{1}^{\prime}\right)\right]\left[\mathrm{H}_{2} \mathrm{O}\right] \\
& \quad+2 k_{-2}\left[\mathrm{H}^{+}\right][(2)]\left[\mathrm{H}_{2} \mathrm{O}\right]+\left(k_{-30}\left[\mathrm{H}_{2} \mathrm{O}\right]\right. \\
& \left.\quad+k_{-3}\left[\mathrm{H}^{+}\right]\right)[(3)]
\end{aligned}
$$

The formation rate of Urea II is written in eq 10 , referring to eq 6 .

$$
\begin{aligned}
& \mathrm{d}[\text { Urea II }] / \mathrm{d} t=\left\{k_{\mathrm{kt}}\left(\left[\left(\mathbf{1}^{\prime}\right)\right]+2[(\mathbf{2})]\right)\right. \\
& \left.\quad+k_{\mathrm{im}}(2[(\mathbf{3})]+[\mathrm{Add} 2])\right\}[\mathrm{NCO}]\left[\mathrm{H}_{2} \mathrm{O}\right]
\end{aligned}
$$

The rate of NCO consumption is expressed by eq 11 , taking into account the above all the equations (eq $1-10$ ) except for eq 2 ;

$$
\begin{aligned}
& -\mathrm{d}[\mathrm{NCO}] / \mathrm{d} t=k_{-1}\left[\mathrm{H}^{+}\right]\left[\left(\mathbf{1}^{\prime}\right)\right]\left[\mathrm{H}_{2} \mathrm{O}\right] \\
& \quad+2 k_{-2}\left[\mathrm{H}^{+}\right][(2)]\left[\mathrm{H}_{2} \mathrm{O}\right]+\left(k_{-30}\left[\mathrm{H}_{2} \mathrm{O}\right]\right. \\
& \left.\quad+k_{-3}\left[\mathrm{H}^{+}\right]\right)[(3)]+k_{001}\left(\left[\left(\mathbf{1}^{\prime}\right)\right]\right. \\
& \quad+2[(2)])[\mathrm{NCO}]+2 k_{003}[(3)][\mathrm{NCO}] \\
& \quad+2\left\{k_{\mathrm{kt}}\left(\left[\left(\mathbf{1}^{\prime}\right)\right]+2[(2)]\right)+k_{\mathrm{im}}(2[(\mathbf{3})]\right. \\
& \quad+[\mathrm{Add} 2])\}[\mathrm{NCO}]\left[\mathrm{H}_{2} \mathrm{O}\right]
\end{aligned}
$$

\section{RESULTS AND DISCUSSION}

\section{DSPUU Reactions in the Absence of Acid Catalyst}

Determination of (1) Rate Constants $\left(k_{001}, k_{001}, k_{003}\right.$, and $\left.k_{004}\right)$ for Reactions of ITPP with (1') ((2)) or (3) and (2) Catalyst Constants $\left(k_{\mathrm{kt}}\right.$ and $\left.k_{\mathrm{im}}\right)$ for Reactions of ITPP with Water. Figure 2 shows the experimental plots of the concentration ratio of the unreacted $\mathrm{NCO}$ groups to initial $\mathrm{NCO}$ groups, $[\mathrm{NCO}] /[\mathrm{NCO}]_{0} v s$. reaction time for the model reactions of ITPP with the mixture of $N$-isopropylidenebutylamine and water (O) or mixture of 2-pentamethylenoimidazolidine and water $(\square)$. The best-fitted plots by the least-square fitting method are also shown in the figure. Table $I$ lists rate and catalyst constants such as $k_{001}, k_{002}$, and $k_{\mathrm{kt}}$ as well as $k_{003}, k_{004}$, and $k_{\text {im }}$ estimated by the fitting procedures. The reactivity

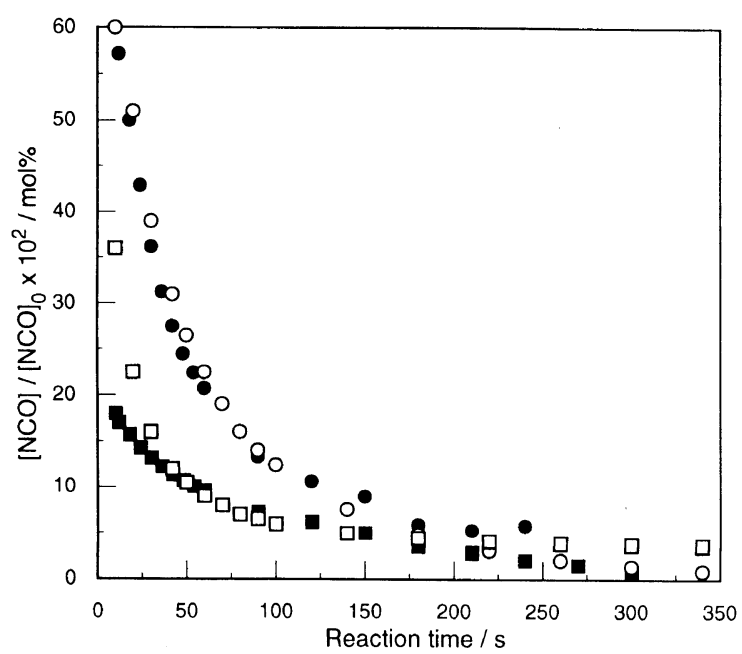

Figure 2. Plots of $[\mathrm{NCO}] /[\mathrm{NCO}]_{0} v s$. reaction time for the model reactions of ITPP with the mixture of $N$-isopropylidenebutylamine and water $(\odot$, experimental; $\bigcirc$, calculated) as well as with the mixture of 2-pentamethylenoimidazolidine and water in chloroform ( $\square$, experimental; $\square$, calculated). 
H. Hanahata et al.

Table I. Estimated rate and catalyst constants of elementary DSPUU reactions

\begin{tabular}{|c|c|c|c|c|c|c|c|c|c|}
\hline \multicolumn{4}{|c|}{$\begin{array}{l}\text { Catalyst constants of reformation reactions } \\
\text { of amino groups }{ }^{\mathrm{a}}\end{array}$} & \multicolumn{4}{|c|}{ Rate constants of direct reactions } & \multirow{2}{*}{\multicolumn{2}{|c|}{$\begin{array}{l}\begin{array}{l}\text { Catalyst constants of } \\
\text { NCO-water reaction }\end{array} \\
\mathrm{kg}^{2} \mathrm{~mol}^{-2} s^{-1}\end{array}$}} \\
\hline \multicolumn{4}{|c|}{$\mathrm{kg}^{2} \mathrm{~mol}^{-2} \mathrm{~s}^{-1}$} & \multicolumn{4}{|c|}{$\mathrm{kg} \mathrm{mol}^{-1} \mathrm{~s}^{-1}$} & & \\
\hline$k_{-1}$ & $k_{-2}$ & $k_{-30}{ }^{b}$ & $k_{-3} \mathrm{~b}$ & $k_{001}$ & $k_{002}$ & $k_{003}$ & $k_{004}$ & $k_{\mathrm{kt}}$ & $k_{\mathrm{im}}$ \\
\hline $8.5 \times 10^{-2}$ & $5.2 \times 10^{-2}$ & $2.4 \times 10^{-2}$ & $4.3 \times 10^{-3}$ & $5.0 \times 10^{-3}$ & 0.32 & $\begin{array}{l}5.0 \times 10^{-2} \\
(0.2)^{\mathrm{c}}\end{array}$ & $\begin{array}{c}0.61 \\
(1.2)^{\mathrm{c}}\end{array}$ & $2.1 \times 10^{-2}$ & $\begin{array}{l}6.8 \times 10^{-2} \\
\left(2.3 \times 10^{-1}\right)^{\mathrm{c}}\end{array}$ \\
\hline
\end{tabular}

${ }^{\mathrm{a}}$ Estimated in ref $3 .{ }^{\mathrm{b}} \mathrm{kg} \mathrm{mol}^{-1} \mathrm{~s}^{-1}$. ${ }^{\mathrm{c}}$ Uncorrected values for the model reaction. See the text.

Table II. Calculation conditions for DSPUU reactions and mol fractions of by-product (Urea II) in PUUs

\begin{tabular}{|c|c|c|c|c|c|c|c|c|c|c|c|}
\hline \multirow{3}{*}{ Sample code } & \multicolumn{3}{|c|}{ Preparation conditions for AEs } & \multicolumn{6}{|c|}{$\begin{array}{l}\text { Initial concentrations of each compound in AEs } \\
\text { and ITPP } / \mathrm{mol} \mathrm{kg}^{-1}\end{array}$} & \multirow{3}{*}{$\frac{\begin{array}{c}{[\text { Acid }]^{\mathrm{a}}} \\
\times 10^{3}\end{array}}{\text { mol kg }{ }^{-1}}$} & \multirow{3}{*}{$\begin{array}{c}\begin{array}{c}\text { Mol fraction } \\
\text { of Urea II }\end{array} \\
\text { mol\% }\end{array}$} \\
\hline & \multirow{2}{*}{$\begin{array}{l}\text { Sample } \\
\text { code }\end{array}$} & \multirow{2}{*}{$\begin{array}{c}{[\text { Acetone }]_{0} /} \\
{[\mathrm{EDA}]_{0}}\end{array}$} & \multirow{2}{*}{$\begin{array}{l}{\left[\mathrm{H}_{2} \mathrm{O}\right]_{0} /} \\
{[\mathrm{EDA}]_{0}}\end{array}$} & \multicolumn{5}{|c|}{$\mathrm{AE}$} & \multirow{2}{*}{$\frac{\text { ITPP }}{\text { NCO }}$} & & \\
\hline & & & & EDA & (1) & (2) & (3) & $\mathrm{H}_{2} \mathrm{O}$ & & & \\
\hline DSPUU2 & AE2 & 1.4 & - & 0.0117 & 0.0573 & 0.0483 & 0.2067 & 0.3606 & 0.6479 & - & 28 \\
\hline DSPUU3 & AE3 & 1.8 & - & 0.0068 & 0.0569 & 0.0794 & 0.1916 & 0.4073 & 0.6431 & - & 36 \\
\hline DSPUU5 & AE5 & 3.0 & - & 0.0022 & 0.0478 & 0.1245 & 0.1400 & 0.4368 & 0.6290 & - & 50 \\
\hline DSPUU6 & AE6 & 1.4 & 0.5 & 0.0149 & 0.0581 & 0.0391 & 0.2109 & 0.5087 & 0.6460 & - & 36 \\
\hline DSPUU7 & AE7 & 2.5 & 0.5 & 0.0074 & 0.0583 & 0.0567 & 0.1981 & 0.5303 & 0.6412 & - & 36 \\
\hline DSPUU8 & AE6 & 1.4 & 0.5 & 0.0149 & 0.0581 & 0.0391 & 0.2109 & 0.5087 & 0.6460 & 0.70 & 16 \\
\hline DSPUU9 & AE6 & 1.4 & 0.5 & 0.0149 & 0.0581 & 0.0391 & 0.2109 & 0.5087 & 0.6460 & 1.05 & 12 \\
\hline DSPUU10 & AE6 & 1.4 & 0.5 & 0.0149 & 0.0581 & 0.0391 & 0.2109 & 0.5087 & 0.6460 & 1.75 & 4 \\
\hline DSPUU11 & AE6 & 1.4 & 0.5 & 0.0149 & 0.0581 & 0.0391 & 0.2109 & 0.5087 & 0.6460 & 3.50 & 0 \\
\hline
\end{tabular}

Note: Reaction conditions including raw materials, reaction temperature (time) and the by-product contents are originated from ref $1 .{ }^{a}$ Acetic acid. ${ }^{\mathrm{b}} 10^{2}[$ Urea II $] /([$ Urea I $]+[$ Urea II $])(\mathrm{mol} \%)$

of the direct reaction of ITPP with $\left(\mathbf{1}^{\prime}\right),(\mathbf{2})$, and (3) as well as the catalytic effects of these compounds on the side reaction of ITPP with water were quantified in terms of rate and catalyst constants. In Table I, $k_{-1}$ and $k_{-2}$ are known catalyst constants of the acid-catalyzed reformation reactions of amino groups from the ketimine groups of $\left(1^{\prime}\right)$ and (2), respectively. $k_{-30}$ and $k_{-3}$ are the catalyst constants of water- and acid-catalyzed ring opening reaction of (3).

Using the six rate and catalyst constants estimated from the model reactions as well as $k_{-30}$, the $Y_{\text {Urea II }}$ for DSPUU2 was first calculated by substituting these constants in eq $1-11$ and solving the equations simultaneously. The concentration of $\left[\mathrm{H}^{+}\right]$is zero in this case. $Y_{\text {Urea II }}$ was $13.1 \%$, far smaller than the experimental $Y_{\text {Urea II }}$ of $28 \%$ (Table II). Explanation for this discrepancy can be found by comparing the calculated [NCO]/ $[\mathrm{NCO}]_{0}$ plots with the experimental ones (Figure 3 ); the calculated plots ( $\square$ ) deviated downwards from the experimental plots (O) up to $c a$. $75 \mathrm{~s}$ of $t_{\mathrm{Ds}}$ and then turned upwards till the end of the DSPUU reaction (400s). This suggests that (1) the rate constants of $k_{001}$ and/or $k_{003}$ must be larger compared to the 'real' constants of the corresponding elementary reactions in the DSPUU reaction and (2) consequently other constants such as $k_{002}$ and $k_{\mathrm{kt}}\left(k_{004}\right.$ and $\left.k_{\text {im }}\right)$ should also be changed. Taking into account the similarity of the chemical structures between $N$-isopropylidenebutylamine and $\left.\left(\mathbf{1}^{\prime}\right)(\mathbf{2})\right)$ rather than between 2-pentamethylenoimidazolidine and (3), we decided to fix $k_{001}, k_{002}$, and $k_{\mathrm{kt}}$ and adjust $k_{003}, k_{004}$, and $k_{\mathrm{im}}$ so as to fit the calculated $Y_{\text {Urea II }} \mathrm{S}$ as well as the calculated [NCO]/ 830

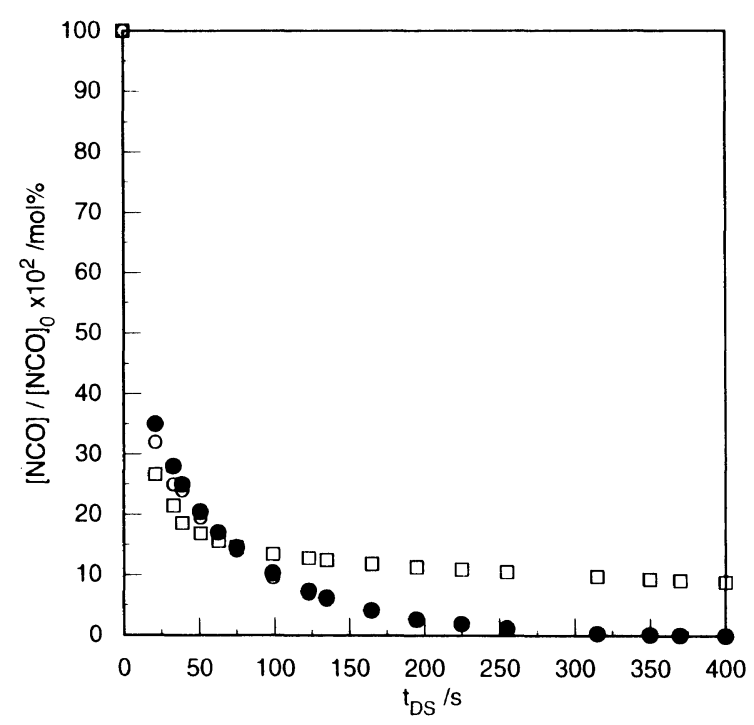

Figure 3. Reaction time ( $\left.t_{\mathrm{DS}}\right)$-NCO consumption plots for DSPUU2 reaction ( $\square$, calculated plots by using $k_{003}, k_{004}$, and $k_{\text {im }}$ estimated by the model reaction; $\bigcirc$, fitted plots; experimental plots).

$[\mathrm{NCO}]_{0}$ plots to the experimental data. Using the adjusted $k_{003}, k_{004}$, and $k_{\mathrm{im}}$ listed in Table I, the recalculated $Y_{\text {Urea II }}$ was $27.89 \%$ and calculated [NCO]/ $[\mathrm{NCO}]_{0}$ plots $(\mathrm{O})$ fit the experimental plots (Figure 3). For further validation of these constants adjusted, other $Y_{\text {Urea II }}$ S were calculated for DSPUU3 - 5. The calculation conditions are listed in Table II. Figure 4 shows the calculated plots of $Y_{\text {Urea II }} v s$. initial concentration ratio of acetone to EDA, [acetone $]_{0} /[\mathrm{EDA}]_{0}$ for the preparation of AE samples (AE2-5), together with the ex- 


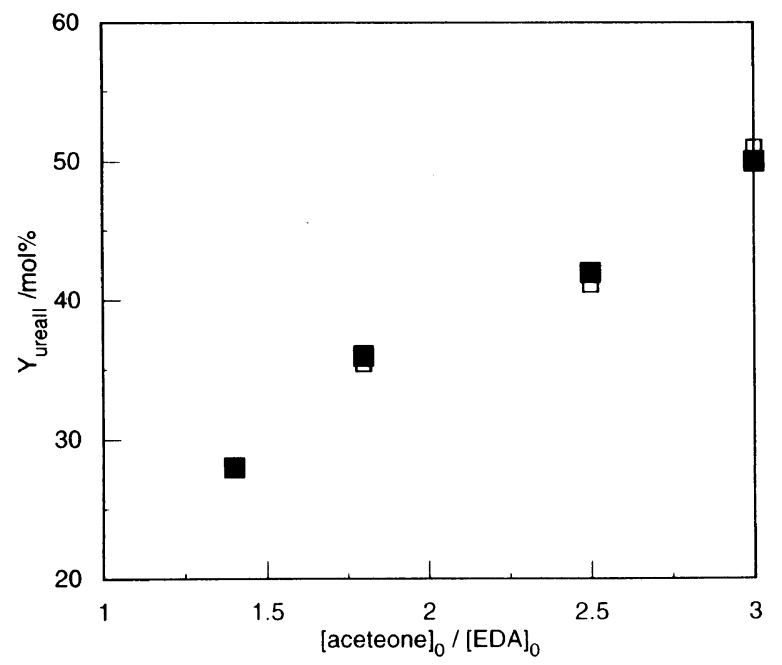

Figure 4. [acetone $]_{0} /[\mathrm{EDA}]_{0}$ dependence of $Y_{\text {Urea II }}$ for DSPUU2-5 reactions ( $\square$, experimental plots; $\square$, calculated plots).

perimental plots. With increasing ratio, calculated $Y_{\text {Urea II }} \mathrm{S}$ increased, agreeing quite well with the experimental data for all DSPUU reactions.

From the above results we may reasonably conclude that the elementary reactions involving in the DSPUU reaction in the absence of an acid are aligned in the order of magnitude of the rate constants; (i) direct reaction of an NCO group with (3) $\left(k_{003}=5.0 \times 10^{-2} \mathrm{~kg} \mathrm{~mol}^{-1} \mathrm{~s}^{-1}\right)$, (ii) reformation reaction of an amino group from (3) (water-catalyzed ring opening reaction) $\left(k_{-30}=2.4 \times\right.$ $10^{-2} \mathrm{~kg} \mathrm{~mol}^{-1} \mathrm{~s}^{-1}$ ), and (iii) reaction of an NCO group with the ketimine groups of $\left(\mathbf{1}^{\prime}\right)$ and (2) $\left(k_{001}=5.0 \times 10^{-3}\right.$ $\left.\mathrm{kg} \mathrm{mol}^{-1} \mathrm{~s}^{-1}\right)$. The side reactions of an NCO group with water, subject to catalysis of the ketimine groups and the imino groups of (3) and Adduct 2 (catalyst constants of $k_{\mathrm{kt}}=2.1 \times 10^{-2}$ and $k_{\mathrm{im}}=6.8 \times 10^{-2} \mathrm{~kg}^{2} \mathrm{~mol}^{-2} \mathrm{~s}^{-1}$, respectively) take place simultaneously. The reactions are summarized in Scheme 1.

Effects of Concentration of Ketimine or Imino Group in DSPUU Reactions on $Y_{\text {Urea II }}$ Figures 5a, b, and c show concentration changes of the ketimine groups, water, and the imino groups during DSPUU2 - 5 reactions, respectively. Note that the concentrations of the ketimine groups and imino groups were equivalent to $\left[\left(\mathbf{1}^{\prime}\right)\right]+$ $2[(2)]$ and $2[(3)]+[\operatorname{Add} 2]$, respectively. With increasing ratio of $[\text { acetone }]_{0} /[\mathrm{EDA}]_{0}$ (see AE2-5 samples in Table II), the concentrations of the ketimine groups and water during the DSPUU reactions were kept higher (Figures $5 \mathrm{a}$ and $\mathrm{b}$ ), while the concentrations of the imino groups were lower (Figure 5c). These results clearly explain the positive correlation between [acetone] / [EDA $]_{0}$ and $Y_{\text {Urea II }}$ depicted in Figure 4. $Y_{\text {Urea II }}$ s may thus be mainly controlled by the initial concentration of the ketimine groups (or water). From the rapid disappearance of the imino groups shown in Figure 5c, the catalytic effect of the imino groups on the $Y_{\text {Urea II }}$ appears to be smaller than that of the ketimine groups, as also described in the previous paper. ${ }^{1}$ However, Figure $6 \mathrm{a}$ shows that the Urea II was formed rapidly up to $100 \mathrm{~s}$ by the strong catalytic effect $\left(k_{\mathrm{im}}=6.8 \times 10^{-2} \mathrm{~kg}^{2} \mathrm{~mol}^{-2}\right.$ $\mathrm{s}^{-1}$ ) of the imino groups and immediately faded away due to the rapid disappearance of the imino groups $\left(k_{-30}=2.4 \times 10^{-2} \mathrm{~kg} \mathrm{~mol}^{-1} \mathrm{~s}^{-1}\right)$. In the case of the (a)

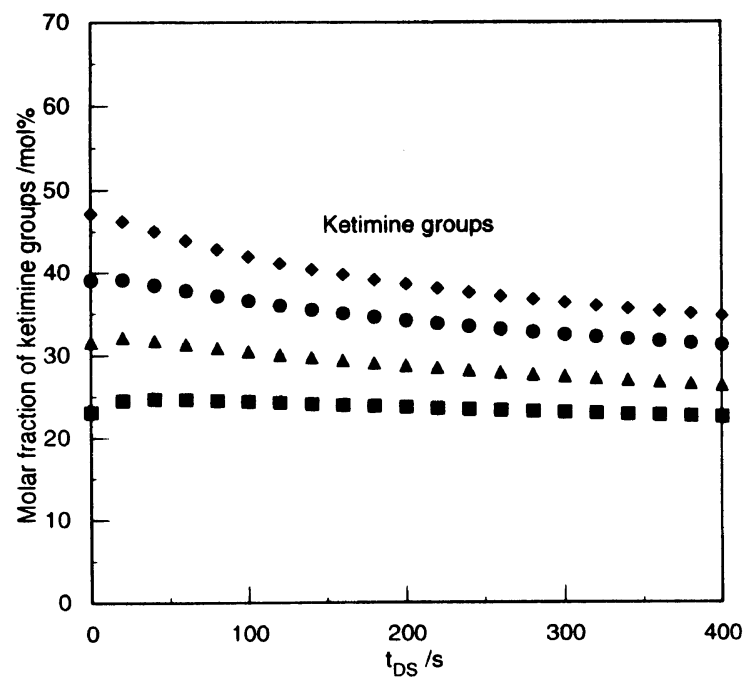

(b)

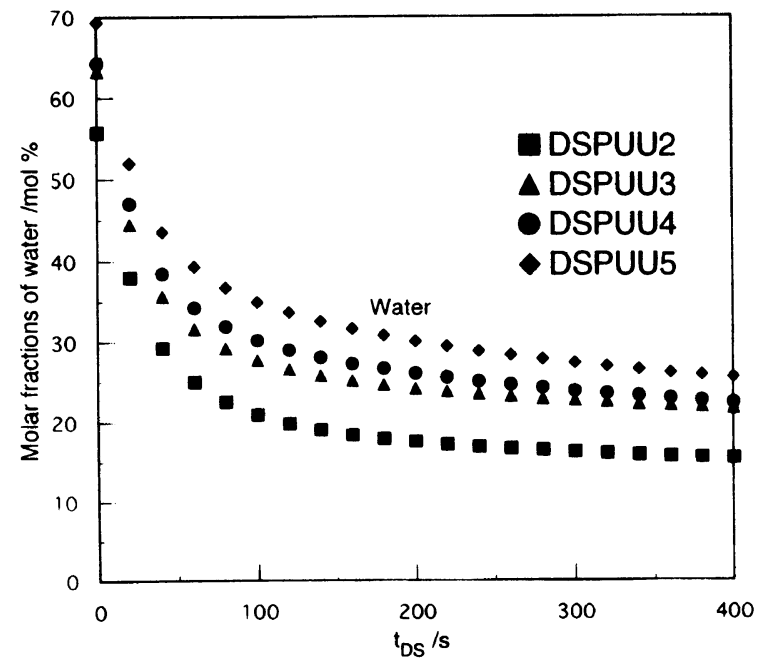

(c)

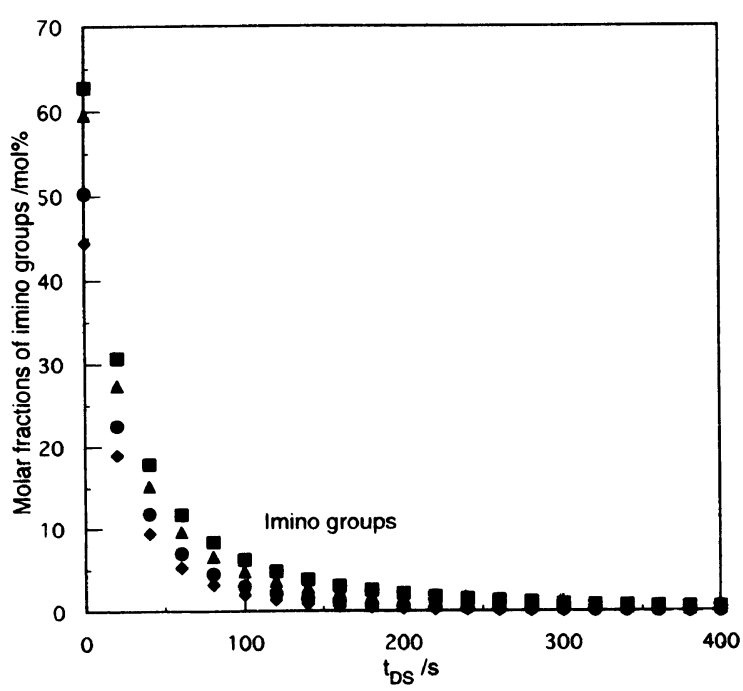

Figure 5. Calculated changes of molar fractions of (a) ketimine groups, (b) water, and (c) imino groups with $t_{\mathrm{DS}}$ for DSPUU2-5 reactions.

DSPUU2 reaction, Urea II formed by the imino group catalyst reached $75.3 \%$ in terms of $Y_{\text {Urea II }}$ (at $400 \mathrm{~s}$ ). Since $Y_{\text {Urea II }}$ depends on the products of the first and second 
(a)

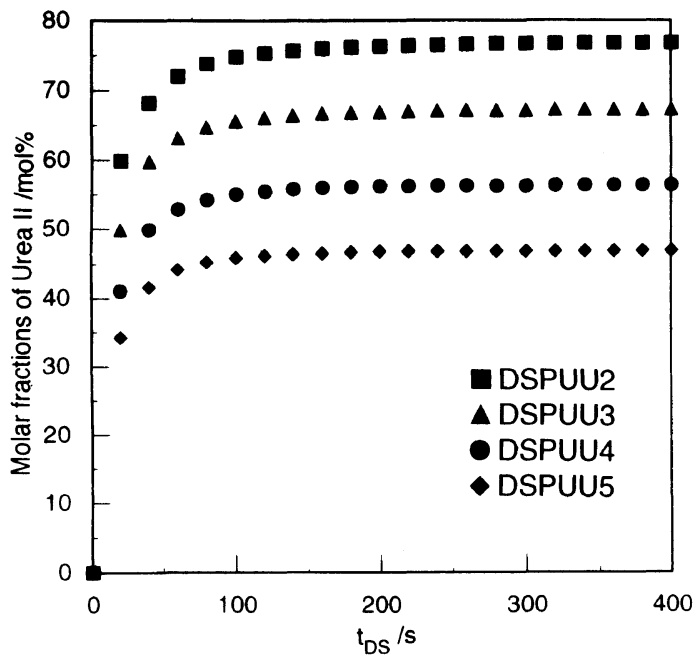

(b)

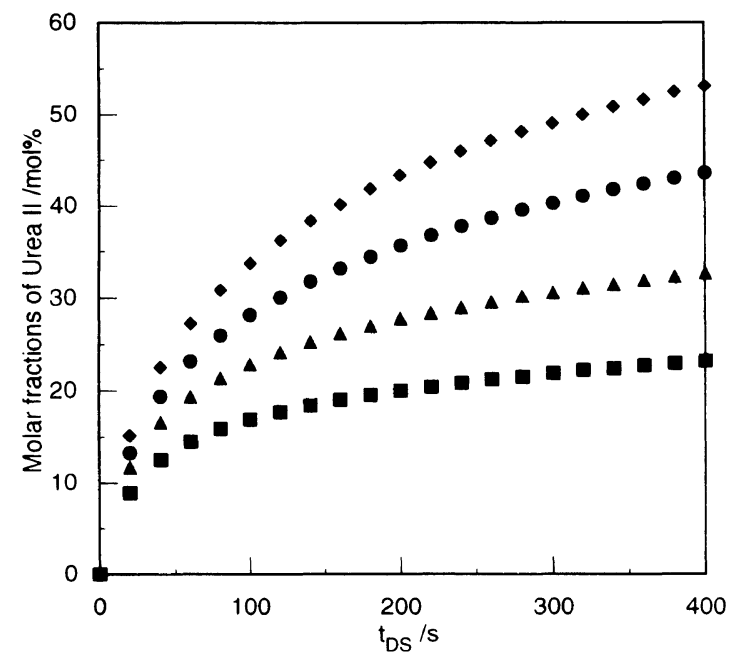

Figure 6. Calculated changes of molar fractions of Urea II formed with $t_{\mathrm{DS}}$ (a) by imino catalyst and (b) by ketimine catalyst.

terms of eq 10, with decreasing initial concentrations of the imino groups (corresponding to decrease of the contribution of the first term), the catalytic effect fades away and the ketimine catalyst becomes important (Figure 6b). For example, when the initial concentration ratio of the ketimine groups to the imino groups of (3) was $2 / 3$, corresponding to that in the equilibrated composition of the AE prepared at [acetone $]_{0} /[\text { EDA }]_{0}$ of 1.8, about half the resultant Urea II was formed by the ketimine catalyst (the imino catalyst). The formation rate of Urea II by the ketimine catalyst was slow and amount of Urea II gradually increased in accordance with the comparably small catalytic effect of the ketimine $\left(k_{\mathrm{kf}}=2.1 \times 10^{-2} \mathrm{~kg}^{2} \mathrm{~mol}^{-2} \mathrm{~s}^{-1}\right)$ and slow consumption rate of the ketimine $\left(k_{001}=5.0 \times 10^{-3} \mathrm{~kg} \mathrm{~mol}^{-1} \mathrm{~s}^{-1}\right)$.

Effects of Addition of Water on $Y_{\mathrm{Urea}} \mathrm{II}^{S}$. The effects of addition of water to the AE samples on $Y_{\text {Urea II }}$ s can also be explained similarly. In the case of DSPUU6 reaction in which the AE6 sample was prepared by adding a certain amount of water to the AE2, the experimental $Y_{\text {Urea II }}(36 \%$ in Table II) is in agreement with that calculated $(36.96 \%)$ for the DSPUU6. The concentra- (a)

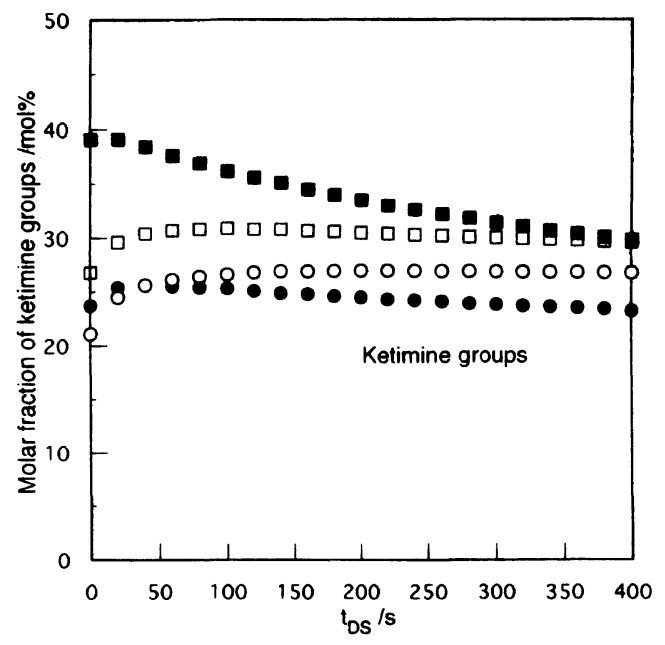

(b)

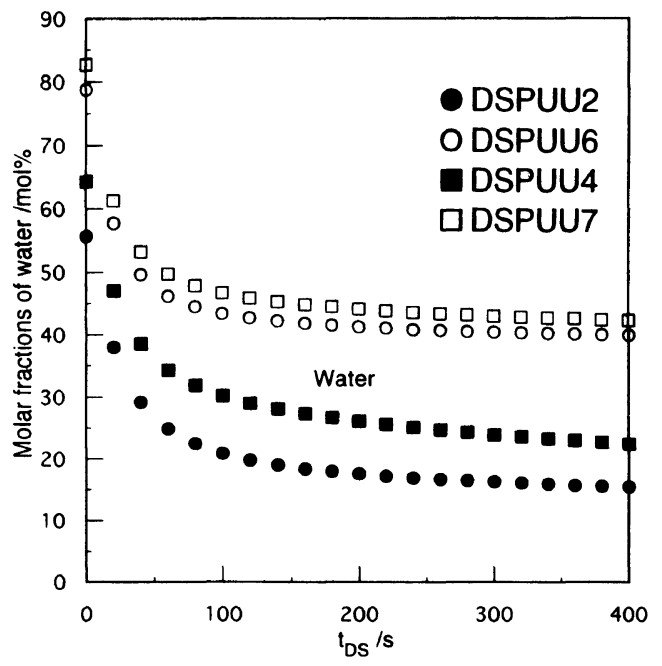

(c)

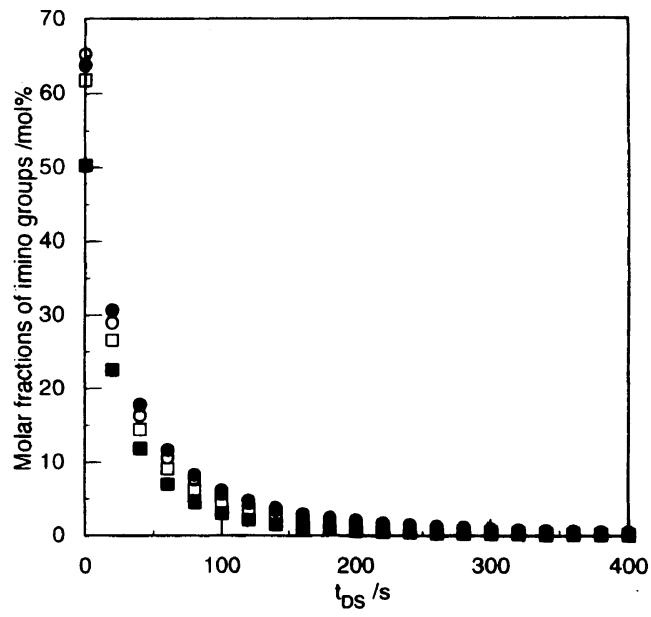

Figure 7. Calculated changes of molar fractions of (a) ketimine groups, (b) water, and (c) imino groups with $t_{\mathrm{DS}}$ for DSPUU2, 4, 6, and 7 .

tions of the ketimine groups and water were kept higher during the DSPUU6 reaction (Figures 7a and b) than those of the DSPUU2 except for the reaction time up to $c a$. $50 \mathrm{~s}$ with respect to the ketimine groups. The 
concentration of the imino groups for the DSPUU6 was lower throughout the reaction except at the beginning of the reaction. Thus, increase in $Y_{\text {Urea II }}$ for the DSPUU6 by $8 \%$ in comparison to that for the DSPUU2 should be attributable to increase in the ketimine and water concentrations at the later reaction stage. The slightly higher increase in concentration of the imino group in the DSPUU6 reaction at the very first stage would also contribute to increase in $Y_{\text {Urea II. }}$.

In similar reactions of DSPUU4 and 7 the experimental $Y_{\text {Urea II }}$ s were 42 and $36 \%$ (the calculated value, $38.93 \%$ ), respectively. The difference of the experimental $Y_{\text {Urea II }}$ by $6 \%$ is ascribed to the significant decrease in the concentrations of the ketimine groups throughout the DSPUU7 reaction (Figure 7a), not to the increase in the concentrations of water and strong catalyst, the imino groups (Figures $7 \mathrm{~b}$ and $\mathrm{c}$ ).

Similar effect of water on decrease in $Y_{\text {Urea II }}$ was observed in the case of the DSPUU model reactions of phenylisocyanate in replace of MDI with AE samples in chloroform. $^{2}$ 1,3-Diphenylurea which corresponds to Urea II in DSPUU reaction was formed in $41 \mathrm{~mol} \%$ using an AE sample consisting of $51 \mathrm{~mol} \%$ of imino (NH) groups and $31.5 \mathrm{~mol} \%$ of ketimine groups. When an $\mathrm{AE}$ sample was prepared in the presence of water and contained 46 and $29.5 \mathrm{~mol} \%$ of $\mathrm{NH}$ and ketimine groups, respectively, the yield of 1,3-diphenylurea decreased to $27 \mathrm{~mol} \%$. The latter result is attributable to the decrease in the initial concentrations of $\mathrm{NH}$ and ketimine groups. In a somewhat different model reaction where the $\mathrm{AE}$ sample was prepared from cyclohexanone and EDA, containing $93 \mathrm{~mol} \%$ of $\mathrm{NH}$ groups of 2-pentamethylenoimidazolidine and only $6 \mathrm{~mol} \%$ of ketimine groups of $N, N^{\prime}$-dicyclohexylideneethylenediamine, the yield of 1,3diphenylurea was $31 \mathrm{~mol} \%$. Similar reaction products prepared in the presence of water resulted in the significant decrease of $Y_{\text {Urea II }}(12 \%)$, although there was little change in the composition ( 95 and $4 \mathrm{~mol} \%$ of $\mathrm{NH}$ and ketimine groups, respectively). Since both reaction products from the ketone-EDA involved little ketimine groups, water might have accelerated the rate of the disappearance of the imino groups of the Adduct 2, leading to lower yield of 1,3-diphenylurea. ${ }^{2}$

\section{DSPUU Reactions in the Presence of Acid Catalyst}

In the DSPUU reaction in the presence of an acid, the following acid-catalyzed reactions ought to be considered in addition to elementary reactions that take place in the absence of the acid: (i) the acid-catalyzed reformation reactions (Scheme 2) of the amino groups from the ketimine groups of $\left(\mathbf{1}^{\prime}\right)$ and (2) (catalyst constants of $k_{-1}$ and $k_{-2}$, respectively in Table I), (ii) ring opening reaction of (3) supported by acid catalysis, and (iii) there is the possibility of acid-catalyzed direct reactions of NCO groups with the ketimine groups and also with (3). In the case of (iii), the addition reaction of NCO groups with the ketimine groups or (3) occurs first, followed by the hydrolysis reaction of Adduct 1 for the former reaction or of Adduct 2 for the latter. As mentioned previously, ${ }^{1}$ acid-catalysis for these addition reactions seems unlikely, while expected for the hydrolysis of the Adducts. However, since the addition reactions are the rate-determining steps for ITPP-ketimine and ITPP-NH

Polym. J., Vol. 29, No. 10, 1997

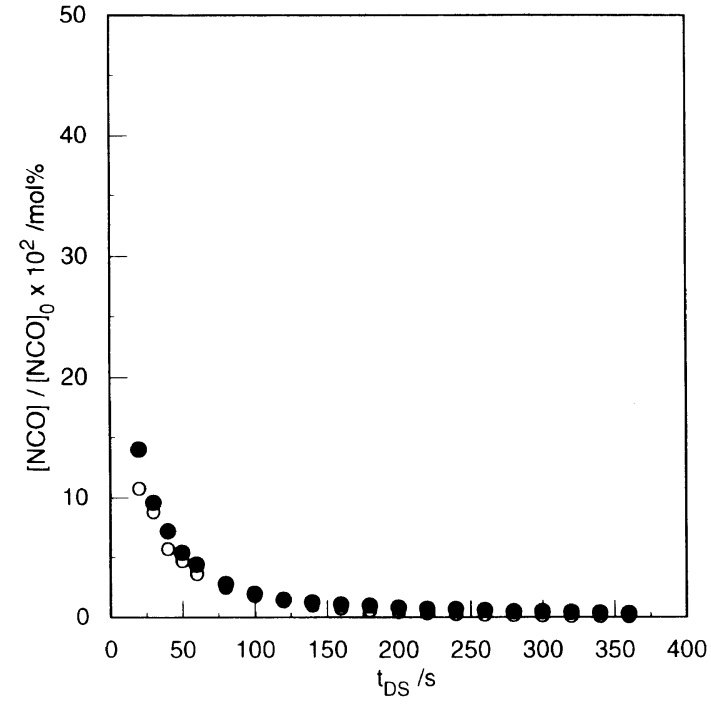

Figure 8. Reaction time $\left(t_{\mathrm{DS}}\right)$ vs. NCO consumption plots for DSPUU11 in the presence of acid catalyst ( $)$, experimental; $O$, calculated).

reactions (Table I), the acid-catalyzed hydrolysis reactions influence much less the yield of Urea II than the acid-catalyzed reformation reactions of amino groups of (1') above mentioned (Scheme 2).

Acid-Catalyzed Regeneration Reactions of Amino Groups from (1'), (2), and (3). To make the acid-catalyzed DSPUU reaction more complicated, the acid species in the AE preparation reactions are different ${ }^{3}$ from that in DSPUU reactions. The protonated amine $\left(\mathrm{H}_{3}{ }^{+} \mathrm{N}-\mathrm{R}\right)$ is the active species for the former and proton and/or acid itself is for the latter. Assuming that the active acid species is $\mathrm{H}^{+}$only, the concentration of $\mathrm{H}^{+}$is expressed in eq 12.

$$
\left[\mathrm{H}^{+}\right]=\sqrt{K_{\mathrm{HA}}\left[\mathrm{CH}_{3} \mathrm{COOH}\right]}
$$

where $K_{\mathrm{HA}}$ and $\left[\mathrm{CH}_{3} \mathrm{COOH}\right]$ are the dissociation constant of acetic acid added and its concentration, respectively. The catalyst constants for the hydrolysis reaction of $\left(\mathbf{1}^{\prime}\right)$ as a representative in the DSPUU reaction can be written in eq 13

$$
k_{-1}=\gamma k_{-1\left(\mathrm{NH}_{3} \mathrm{R}\right)}
$$

where $\gamma$ is the proportion constant and $k_{-1\left(\mathbf{N H}_{3} \mathbf{R}\right)}$ is the catalyst constant in the case of the $\mathrm{AE}$ reaction. Combining eq 12 and 13 simply gives

$$
k_{-1}\left[\mathrm{H}^{+}\right]=\gamma \sqrt{K_{\mathrm{HA}}} k_{-1\left(\mathrm{NH}_{3} \mathrm{R}\right)} \sqrt{\left[\mathrm{CH}_{3} \mathrm{COOH}\right]}
$$

$k_{-1\left(\mathrm{NH}_{3} \mathrm{R}\right)}$ and $\sqrt{\left[\mathrm{CH}_{3} \mathrm{COOH}\right]}$ are known and thus, the left side can be estimated, provided that the parameter $\gamma \sqrt{K_{\mathrm{HA}}}$ is determined. A similar relation as eq 14 holds for other catalyst constants such as $k_{-2}$ and $k_{-3}$. An attempt was made to determine the above parameter by fitting the calculated plots of $[\mathrm{NCO}] /[\mathrm{NCO}]_{0}$ as a function of $t_{\mathrm{DS}}$ to the experimental plots (Figure 8) for the DSPUU11 reaction. The calculated plots were obtained by substituting the $k_{-1}\left[\mathrm{H}^{+}\right], k_{-2}\left[\mathrm{H}^{+}\right]$, and $k_{-3}\left[\mathrm{H}^{+}\right]$into eq $1-11$ and solving them. In a similar way, the parameters were estimated for DSPUU8-10 and averaged. By using the average value, the calculated $Y_{\text {Urea II }}$ f for DSPUU8-11 are plotted in Figure 9. The 


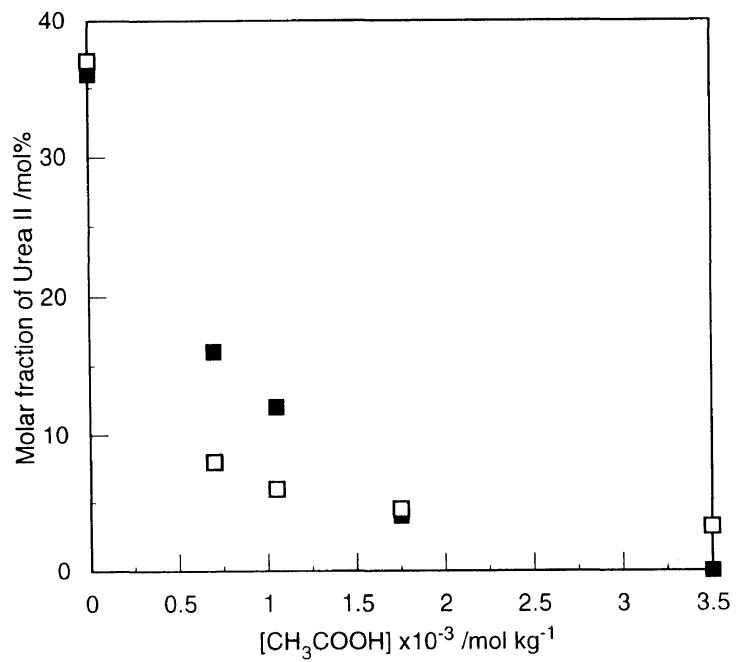

Figure 9. Acid concentration dependence of $Y_{\text {Urea II }}$ for DSPUU6, 8 , 9,10 , and 11 ( $\square$, experimental; $\square$, calculated).

(a)

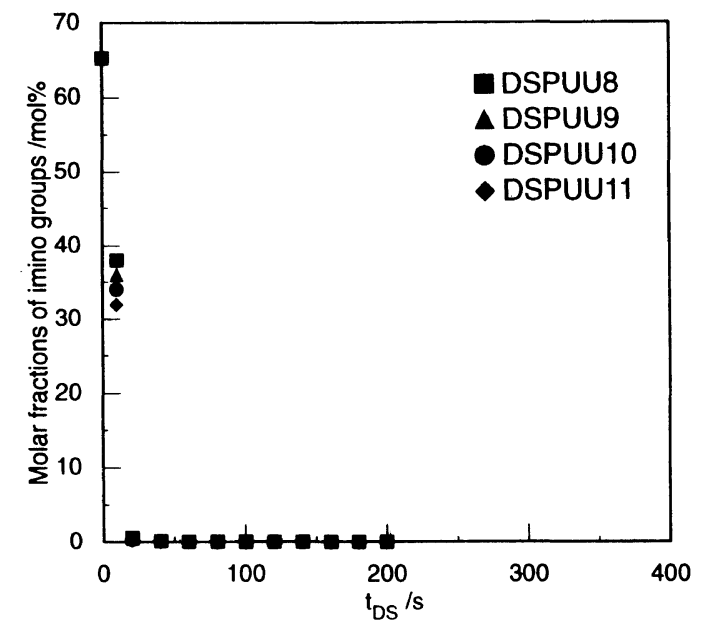

(b)

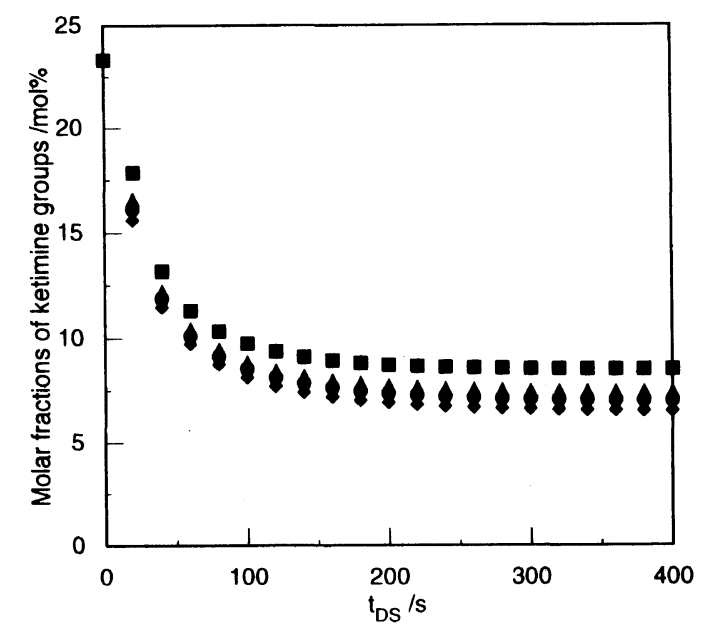

Figure 10. Calculated changes of molar fractions of (a) imino groups and (b) ketimine groups with $t_{\mathrm{DS}}$ for DSPUU8-11.

calculated $Y_{\text {Urea II }}$ for the DSPUU6 in the absence of acid is also plotted in Figure 9. The calculated $Y_{\text {Urea II }} \mathrm{S}$ abruptly decreased and almost leveled off. There is no serious discrepancy between the calculated and experimental data, indicating that acid catalyzed reformation reactions principally take place. Figures $10 \mathrm{a}$ and $\mathrm{b}$ show the time-dependence plots of the calculated concentration of the residual imino groups and ketimine groups for the DSPUU8-11 reactions, respectively. By comparing these results with those for the DSPUU6 in Figures 7c and $a$, it is clear that the presence of the acid is very effective for accelerating the rates of the disappearance of the imino groups in particular and also the ketimine groups, leading to lower $Y_{\text {Urea II }}$ s. Contrary to the complete disappearance of the imino groups, the calculated concentrations of the ketimine groups gradually leveled off even in the latter half of the DSPUU11 reaction. This may be caused by the fact that the NCO groups were consumed by the side reaction with water before reacting with the ketimine groups, forming Urea II (Figure 9). The reason that $Y_{\text {Urea II }}=0$ for the DSPUU11 is not clarified yet, but possibly associated with the neutralization of significant amounts of ketimine groups by acetic acid at that acid concentration so that the $\mathrm{NCO}$-water reaction is completely suppressed.

The calculated concentration $(7.3 \mathrm{~mol} \%)$ of the ketimine groups at the chain ends of the polymer after completion of the DSPUU10 $\left(t_{\mathrm{DS}}=400 \mathrm{~s}\right)$ is comparable to the experimental value $(8.2 \%)$ measured by the end-group analysis. ${ }^{1}$ This indirectly shows that the acid catalyzed reformation reactions take place and the end groups are ketimine groups.

Acknowledgment. The authors thank Dr. Kunihiko Okajima and Dr. Nobuchika Tamura, of Central Laboratory, Asahi Chemical Industry, Co., Ltd. for useful comments and advice.

\section{APPENDIX}

According to the reaction pathway for the direct reaction of ITPP with the ketimine groups in the presence of water in the EXPERIMENTAL, the rates of decrease in the concentration of the $\mathrm{NCO}$ and ketimine groups can be written in eq $\mathrm{A} 1$

$$
-\mathrm{d}[\mathrm{Ket}] / \mathrm{d} t=k_{001}[\mathrm{Ket}][\mathrm{NCO}]
$$

where [Ket] and $k_{001}$ are the concentration of the ketimine groups of $N$-isopropylidenebutylamine and rate constant for the corresponding adduct formation reaction, respectively. The rates of consumption of the adduct, NCO groups, and water can be written in eq A2, $\mathrm{A} 3$, and $\mathrm{A} 4$, respectively.

$$
\begin{aligned}
& -\mathrm{d}\left[\mathrm{Add}_{0}\right] / \mathrm{d} t=-k_{001}[\mathrm{Ket}][\mathrm{NCO}] \\
& \quad+k_{002}\left[\mathrm{Add}_{0}\right]\left[\mathrm{H}_{2} \mathrm{O}\right] \\
& -\mathrm{d}[\mathrm{NCO}] / \mathrm{d} t=k_{001}[\mathrm{Ket}][\mathrm{NCO}] \\
& \quad+2 k_{\mathrm{kt}}[\mathrm{Ket}][\mathrm{NCO}]\left[\mathrm{H}_{2} \mathrm{O}\right] \\
& -\mathrm{d}\left[\mathrm{H}_{2} \mathrm{O}\right] / \mathrm{d} t=k_{002}\left[\mathrm{Add}_{0}\right]\left[\mathrm{H}_{2} \mathrm{O}\right] \\
& +k_{\mathrm{kt}}[\mathrm{Ket}][\mathrm{NCO}]\left[\mathrm{H}_{2} \mathrm{O}\right]
\end{aligned}
$$

where $\left[\mathrm{Add} 1_{0}\right], k_{002}$, and $k_{\mathrm{kt}}$ are the concentration of the adduct, rate constant for Urea $\mathrm{I}^{\prime}$ formation, and catalyst constant of the NCO-water reaction. Here, the rate constant $\left(5.9 \times 10^{-5} \mathrm{~kg} \mathrm{~mol}^{-1} \mathrm{~s}^{-1}\right)$ of $\mathrm{NCO}$-water reaction was neglected. ${ }^{9}$ Similarly the rate of formation of Urea $\mathrm{I}^{\prime}$ and Urea II are written in eq A5 and A6, respectively. 


$$
\begin{aligned}
& \mathrm{d}\left[\mathrm{Urea} \mathrm{I}^{\prime}\right] / \mathrm{d} t=k_{002}\left[\mathrm{Addl}_{0}\right]\left[\mathrm{H}_{2} \mathrm{O}\right] \\
& \mathrm{d}[\text { Urea II }] / \mathrm{d} t=k_{\mathrm{kt}}[\text { Ket }][\mathrm{NCO}]\left[\mathrm{H}_{2} \mathrm{O}\right]
\end{aligned}
$$

Equations A1-A6 were solved numerically by substituting arbitrary values for $k_{001}, k_{002}$, and $k_{\mathrm{kt}}$ into these equations to calculate $[\mathrm{NCO}] /[\mathrm{NCO}]_{0}$ as a function of $t_{\mathrm{DS}}$ and the molar ratio of Urea II at the end of the reaction $\left(t_{\mathrm{DS}}=400 \mathrm{~s}\right)$.

\section{REFERENCES AND NOTES}

1. E. Yamazaki, H. Hanahata, J. Hiwatari, and Y. Kitahama, Polym. J., 29, 811 (1997)

2. Y. Nakano, E. Yamazaki, H. Hanahata, K. Okajima, and Y. Kitahama, Bull. Chem. Soc. Jpn., 70, 1185 (1997).
3. H. Hanahata, E. Yamazaki, and Y. Kitahama, Polym. J., 29, 818 (1997).

4. A reaction of $10.0 \mathrm{~g}(0.17 \mathrm{~mol})$ of extra pure acetone and $6.2 \mathrm{~g}$ $(0.085 \mathrm{~mol})$ of extra pure $n$-butylamine, both of which were purchased from Wako Pure Chemical Industries, Ltd. (Kyoto, Japan) was carried out in a $0.1 \mathrm{~L}$ round-bottomed flask (with a seal cap) over $10 \mathrm{~g}$ of molecular sieve (4A) obtained from the same manufacturer at $50^{\circ} \mathrm{C}$ for $15 \mathrm{~h}$. The unreacted raw materials and water were removed in vacuo $\left(70^{\circ} \mathrm{C} 200 \mathrm{~Pa}^{-1}\right)$. The light yellow liquid was characterized as the desired product ( $91 \%$ purity based on the amine) by ${ }^{1} \mathrm{H}$ NMR.

5. K. Harada, Y. Mizoe, J. Furukawa, and S. Yamashita, Macromol. Chem., 132, 295 (1970).

6. S. Witek, A. Bielawska, and J. Bielawski, Heterocyclics, 14, 1313 (1980).

7. T. Matsui, Y. Arimatsu, and H. Suzuki, Sen-i Gakkaishi, 86, 46 (1993).

8. T. H. Fife and A. M. Pellino, J. Am. Chem. Soc., 23, 3062 (1980).

9. H. Hanahata and J. Hiwatari, unpublished result. 